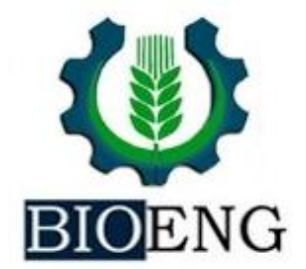

\title{
ÁCIDOS HÚMICOS/FÚLVICOS E NITROGÊNIO NA PRODUTIVIDADE DA CULTURA DO MILHO
}

${ }^{1}$ UTFPR - Universidade Tecnológica Federal do Paraná, Departamento de Ciências Agrárias, Dois Vizinhos, PR, Brasil

${ }^{2}$ UTFPR - Universidade Tecnológica Federal do Paraná, Departamento de Ciências Agrárias, Pato Branco, PR, Brasil

Article history: Received 19 May 2018; Received in revised form 06 August 2018; Accepted 21 August 2018; Available online 30 September 2018.

\section{RESUMO}

O milho possui grande importância para a economia mundial, neste contexto cada vez mais busca-se alternativas para aumentar o rendimento de grãos. O objetivo do estudo foi avaliar os componentes morfológicos e a produtividade de grãos do milho cultivado em diferentes tratamentos com utilização isolada e/ou associada de nitrogênio e ácidos húmicos/fúlvicos. $\mathrm{O}$ estudo foi conduzido na Universidade Tecnológica Federal do Paraná, Campus de Dois Vizinhos, PR, durante a safra 2017/2018. Como fonte de nitrogênio foi utilizado uréia e de ácidos húmicos/fúlvicos um produto comercial (bioestimulante). Utilizou-se delineamento de blocos ao acaso com sete tratamentos e quatro repetições, sendo: 1: aplicação de $1 / 2$ dose do bioestimulante em V4 + aplicação de 1/2 dose em V8; 2: aplicação de dose recomenda do bioestimulante em V4; 3: aplicação de dose recomenda do bioestimulante em V8; 4: nitrogênio; 5: nitrogênio + aplicação de dose recomenda do bioestimulante em V8; 6: nitrogênio + aplicação de dose recomenda do bioestimulante em V4; 7: sem nitrogênio e sem bioestimulante (testemunha). Os ácidos foram aplicados via foliar e o nitrogênio $(\mathrm{N})\left(170 \mathrm{Kg} \mathrm{ha}^{-1}\right)$ em cobertura em V4. Foram avaliados no final do ciclo da cultura as características morfológicas de planta e os componentes de rendimento. Os dados foram submetidos análise de variância e quando constado significância, aplicou-se teste de Scott-Knott a 5\% de probabilidade. A utilização de ácidos húmicos/fúlvicos não interferiu nas características morfológicas das plantas, tampouco sobre os componentes de rendimento do milho e produtividade do milho, seja utilizado isoladamente ou associado com $\mathrm{N}$. $\mathrm{O}$ uso de $\mathrm{N}$ via uréia em cobertura proporciona elevação do número de grãos por fileira e grãos por espiga, massa de mil grãos, produtividade por espiga e área.

Palavras-chave: Zea mays, produção, matéria orgânica, bioestimulante.

\section{HUMIC/FULVIC ACID AND NITROGEN IN THE CORN CROP YIELD}

\begin{abstract}
Corn has great importance to the world economy and due to it, alternatives to increase yield are continuously evaluated. The objective of this study was to evaluate corn crop development and its yield under different treatments with isolated and/or associated use of nitrogen and humic/fulvic acids. The study was carried out at the Universidade Tecnológica Federal do Paraná,
\end{abstract}

\footnotetext{
*vandersonvbatista@ hotmail.com
} 
Dois Vizinhos, PR, during the 2017/2018 growing season. As source of nitrogen was used urea and humic/fulvic acids as a commercial product (biostimulant). A randomized complete block design with seven treatments and four replicates was used: 1: application of 1/2 dose of biostimulant in V4 + application of $1 / 2$ dose in V8; 2: application of full dose of the biostimulant in V4; 3: application of full dose of the biostimulant in V4; 4: nitrogen; 5: nitrogen + application of full dose of the biostimulant in V8; 6: nitrogen + full dose of the biostimulant in V4; 7 : without nitrogen and without biostimulant (control). Acids were applied via leaf and nitrogen (N) $\left(170 \mathrm{Kg} \mathrm{ha}^{-1}\right)$ in sidedress at corn V4. Corn morphological traits, yield components and final yield were evaluated at the end of the crop cycle. Data were submitted to analysis of variance and when significance was found, Scott-Knott test was applied at a 5\% probability. The use of humic/fulvic acids did not interfere in the morphological traits of corn plants, nor on the yield components and final yield, either alone or associated with $\mathrm{N}$. Uréia $\mathrm{N}$ provides an increase in the number of grains per row and grains per spike, thousand grains weight and yield per spike and per area.

Keywords: Zea mays, production, organic matter, biostimulant.

\section{INTRODUÇÃO}

O milho (Zea mays) é um dos cereais mais produzido e consumido no mundo, sendo classificado como a segunda commodity mais negociada, ficando atrás somente da cultura da soja (CONAB, 2018). Dentre os países produtores de milho, o Brasil, com produção de 97 milhões de toneladas na safra 2016/2017, encontra-se na terceira colocação como maior produtor mundial de milho, atrás apenas dos Estados Unidos e China (USDA, 2017). Apesar da produtividade de milho ser elevada, há uma constante busca por maior produtividade $\mathrm{e}$ lucratividade das lavouras, buscando-se sempre novas tecnologias para o cultivo do cereal.

Vários estudos mostram efeitos positivos, no rendimento produtivo do milho, quando utilizado adubação nitrogenada (DOTTO et al., 2010; LANGE et al., 2014; NETO et al., 2016; PANDOLFO et al., 2015). Segundo Coelho et al. (1992), o nitrogênio é um dos principais nutrientes requeridos pela cultura do milho. Já Pandolfo et al. (2015) destacam que a aplicação de nitrogênio em cobertura influencia positivamente o rendimento de grãos de milho, sendo que Dotto et al. (2010) observaram em seus estudos que a utilização de $80 \mathrm{Kg} \mathrm{ha}^{-1}$ de nitrogênio em cobertura, é o suficiente para a produtividade diferir estatisticamente do tratamento que não recebeu adubação nitrogenada.

Quanto aos ácidos húmicos/fúlvicos, estudos demostram que estas sustâncias apresentam capacidade de estimular o desenvolvimento do sistema radicular em diversas espécies, inclusive no milho nos estádios iniciais (ZANDONADI et al., 2007). Porém, poucas informações são encontradas na literatura, retratando se estas substâncias apresentam capacidade de inferir sobre o acúmulo massa seca das plantas, tampouco sobre os componentes de rendimento da cultura do milho. Além de ter poucos estudos, Caron et al. (2015) relatam divergências em estudos com o uso de substâncias húmicas no cultivo de grãos de soja e milho, aonde alguns estudos comprovam o benefício na produtividade destas culturas, porém outros trabalhos são contrários a estes resultados.

Sendo assim, o objetivo do estudo foi avaliar os componentes morfológicos de plantas de milho ao final do ciclo, além dos componentes de produtividade da cultura, cultivado em diferentes tratamentos com 
utilização isolada e/ou associada de nitrogênio e ácidos húmicos/fúlvicos.

\section{MATERIAL E MÉTODOS}

O estudo foi conduzido no Fazenda Experimental da Universidade Tecnológica Federal do Paraná (UTFPR), Câmpus de Dois Vizinhos. A área experimental possui altitude de 530 metros, clima Cfa
(ALVARES et al., 2013) e precipitação de aproximadamente $2.000 \mathrm{~mm}$ ano (IAPAR, 2018). Os dados de temperatura e precipitação constatadas durante a realização do estudo, são representados na Figura 1.

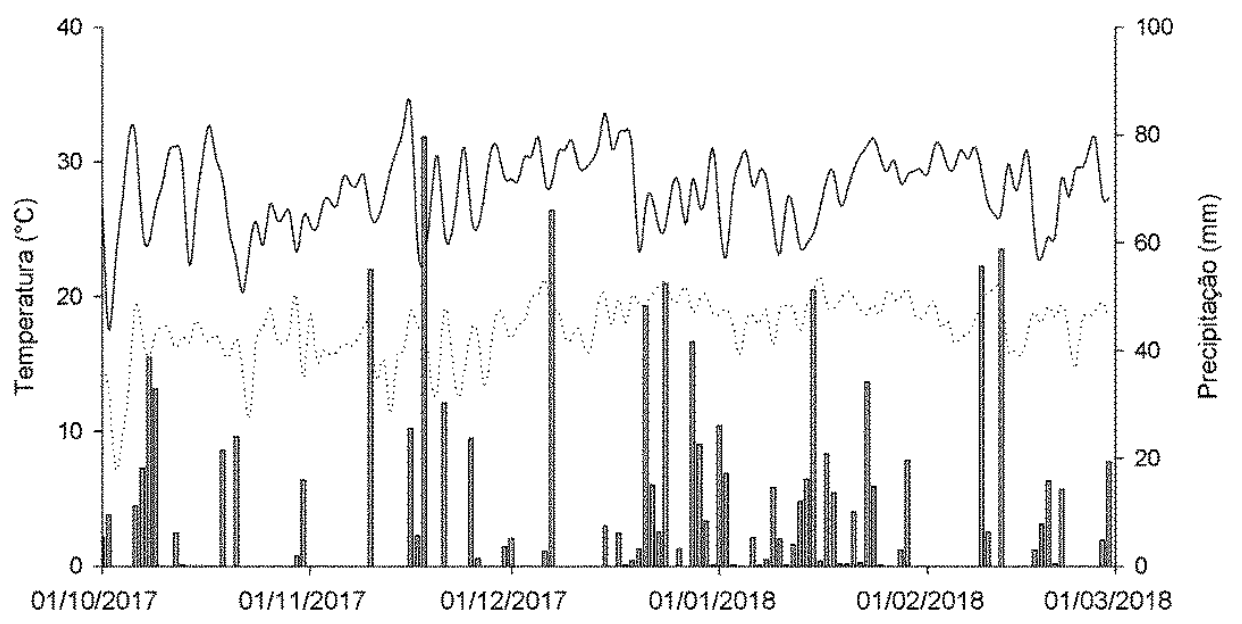

Figura 1. Dados de temperatura máxima $\left({ }^{\circ} \mathrm{C}\right)$, temperatura mínima $\left({ }^{\circ} \mathrm{C}\right)$ e precipitação $(\mathrm{mm})$, registrados pela estação do INMET de Dois Vizinhos - PR, durante o período de condução do estudo.

O solo é classificado como Latossolo Vermelho distrófico (BHERING et al., 2008), com $57 \%$ argila, $33 \%$ silte e $10 \%$ areia, e componentes químicos na profundidade de $0-20 \mathrm{~cm}$ de $3,43,4,30,0,9 \mathrm{e}$ $0,90 \mathrm{cmol}_{\mathrm{c}} \mathrm{dm}^{-3}$ para $\mathrm{H}+\mathrm{Al}, \mathrm{Ca}, \mathrm{Mg}$ e $\mathrm{K}$ respectivamente. Também foram observados valores de $\mathrm{P}\left(21,63 \mathrm{mgdm}^{-3}\right)$, mátria orgânica de 44,23 $\mathrm{mgdm}^{-3}$, com pH 5,20 e saturação por base de $64,08 \%$.

Utilizou-se delineamento de blocos ao acaso, sendo avaliado sete tratamentos com quatro repetições, os quais foram constituídos por diferentes épocas de aplicação de ácidos húmicos/fúlvicos, associados ou não com nitrogênio $(\mathrm{N})$.

Como fonte de ácidos húmicos/fúlvicos foi utilizado um produto comercial (bioestimulante), que segundo Oliveira e Souza (2016) é composto por 0,5\% de N, 16,7\% de ácidos húmicos, 14,0\% de carbono orgânico total, $18,0 \%$ de extrato húmico total, $1,3 \%$ de ácidos fúlvicos, apresenta $\mathrm{pH} 4,0$ e densidade $1,1 \mathrm{gcm}^{-3}$, com recomendação técnica para aplicação de 625 $\mathrm{mL} \mathrm{ha}{ }^{-1}$. A aplicação do bioestimulante foi realizado com um compressor de $\mathrm{CO}_{2}$, sendo acoplado a uma barra com 4 bicos, melhorando a eficiência e distribuição do produto.

A fonte de $\mathrm{N}$ utilizado foi uréia com $45 \%$ de nitrogênio $(\mathrm{N})$, sendo aplicada de forma manual, a lanço e em cobertura na quantidade de $170 \mathrm{Kg} \mathrm{ha}^{-1}$ de $\mathrm{N}$, em estádio vegetativo V4 da cultura do milho.

Os tratamentos avaliados foram: tratamento 1: aplicação de $1 / 2$ dose do bioestimulante em V4 + aplicação de $1 / 2$ dose em V8 (T1); tratamento 2: aplicação de dose recomenda do bioestimulante em V4 (T2); tratamento 3: aplicação de dose recomenda do bioestimulante em V8 (T3); tratamento 4: 
nitrogênio (T4); tratamento 5: nitrogênio + aplicação de dose recomenda do bioestimulante em V8 (T5); tratamento 6: nitrogênio + aplicação de dose recomenda do bioestimulante em V4 (T6); tratamento 7: sem nitrogênio e sem bioestimulante (testemunha) (T7).

As parcelas experimentais foram constituídas de seis linhas de cultivo de milho, com dez metros de comprimento cada, espaçadas de $45 \mathrm{~cm}$ entre linhas. Para as avaliações, foram utilizadas plantas de duas linhas centrais de cada PE, com cinco metros lineares de comprimento, gerando unidades de avaliação (UA) de $4,5 \mathrm{~m}^{2}$.

Devido à grande quantidade de biomassa de aveia (Avena sativa) presente na área experimental, está foi dessecada com o herbicida glyphosate $900 \mathrm{~g}$ i.a. ha ${ }^{-1}, 25$ dias antes da semeadura do milho.

Utilizou-se o híbrido de milho 30F53VYHR, o qual apresenta ciclo precoce, com elevado potencial produtivo e recomendação técnica de cultivo de 70 a 80 plantas ha $^{-1}$ para a região de estudo (DUPONT PIONNER, 2018). A semeadura foi realizada em 2 de outubro de 2017, em sistema de plantio direto com semeadora/adubadora a vácuo, acoplada a um trator. Utilizou-se densidade de semeadura de 80.000 sementes $\mathrm{ha}^{-1}$. Foi utilizado $300 \mathrm{Kg} \mathrm{ha}^{-1}$ da fórmula comercial 13-34-00 ( $\left.\mathrm{N}-\mathrm{P}_{2} \mathrm{O}_{5}-\mathrm{K}_{2} \mathrm{O}\right)$, no momento da semeadura. Também, foi aplicado cloreto de potássio $\left(60 \% \mathrm{~K}_{2} \mathrm{O}\right)\left(150 \mathrm{~kg} \mathrm{ha}^{-1}\right)$, no estádio vegetativo V1.

Para o manejo de plantas daninhas, foi utilizado 5 litros de atrazina $+100 \mathrm{ml}$ de mesotrine $\mathrm{ha}^{-1}$ no estádio fenológico V2. A aplicação da atrazina, foi realizado com um compressor de $\mathrm{CO}_{2}$, acoplado a uma barra com 4 bicos. Também foi aplicado fungicida (piraclostrobina + epoxiconazol) na dose de $0,4 \mathrm{~L} \mathrm{ha}^{-1}$ com pulverizador autopropelido em VT. Considerando que o milho apresentava tecnologia $B t$, não foi realizado aplicação de inseticida.
As avaliações foram realizadas em 16 de fevereiro de 2018 (137 dias após a semeadura). Inicialmente avaliou-se a quantidade de espigas, contando o número de espigas presente em cada UA, sendo o valor extrapolado para hectares (espigas ha ${ }^{1}$ ). Na sequência, foram avaliados o diâmetro do colmo $(\mathrm{cm})$, a altura inserção da espiga (cm) e a altura de planta $(\mathrm{cm})$, sendo estes, mensurados em dez plantas por UA, considerando para a análise estatística o valor médio obtido em cada UA. O diâmetro do colmo foi obtido com auxílio de um paquímetro digital, entre $\mathrm{o}$ primeiro $\mathrm{e}$ segundo entrenó das plantas acima do nível do solo. Os valores de altura de inserção da espiga e altura de planta foram obtidos com auxílio de uma fira métrica, considerando como altura da inserção a distância entre o nível do solo e o entrenó de inserção da espiga principal, e a distância entre o solo e a ponta do pendão, como valores de altura de planta.

Cinco espigas ao acaso por UA foram coletadas, nas quais foram avaliadas a quantidade de grãos por fileira e a quantidade de fileiras por espiga. Realizouse cálculo de média aritmética entre os valores observados em cada variável, sendo este utilizado para a análise de dados. Também, multiplicando-se os valores de grãos por fileira e fileiras por espiga, nas respectivas UA, obtiveram-se os valores de número de grãos por espiga (GE).

A produtividade $\left(\mathrm{Kg} \mathrm{ha}^{-1}\right)$, foi obtida colhendo todas as espigas de cada UA manualmente, com debulha dos grãos realizada em debulhador de cereais, acoplado a um trator. A amostra de grãos foi pesada e a porcentagem de umidade dos grãos mensurada em um determinador digital de umidade. Os valores de massa de grãos obtidas em cada UA foram corrigidos para umidade de $13 \%$ e o valor extrapolado para hectare $\left(\mathrm{Kg} \mathrm{ha}^{-1}\right)$.

Os valores para a variável massa de mil grãos foram obtidos pela pesagem de oito amostras por UA contendo 200 grãos, 
realizado cálculo para de média aritmética entre os valores observados e multiplicado pelo fator de correção cinco, sendo este valor corrigido para umidade de grãos de $13 \%$.

Os dados foram tabulados e submetidos a análise de variância e quando

\section{RESULTADOS E DISCUSSÃO}

Constata-se na Tabela 1 que as variáveis referentes às características agronômicas das plantas de milho não sofreram alterações nos tratamentos constado significância, aplicou-se teste de Scott-Knott a 5\% de probabilidade, com auxílio do software SISVAR 5.6 (FERREIRA, 2008).

Tabela 1. Ácidos húmicos/fúlvicos e nitrogênio sob as características agronômicas de plantas de milho, cultivado na safra 2017/2018. Dois Vizinhos - PR (2018).

\begin{tabular}{cccc}
\hline Tratamentos & $\begin{array}{c}\text { Altura de } \\
\text { planta }(\mathrm{cm})\end{array}$ & $\begin{array}{c}\text { Altura de inserção da } \\
\text { espiga }(\mathrm{cm})\end{array}$ & $\begin{array}{c}\text { Diâmetro basal do } \\
\text { colmo }(\mathrm{cm})\end{array}$ \\
\hline T1 & 268,25 & 143,50 & $2,18^{\mathrm{NS}}$ \\
T2 & 269,15 & 147,90 & 2,29 \\
T3 & 266,10 & 148,50 & 2,26 \\
T4 & 278,00 & 156,30 & 2,32 \\
T5 & 271,90 & 149,25 & 2,34 \\
T6 & 273,60 & 152,45 & 2,34 \\
T7 & 266,65 & 149,00 & 2,21 \\
\hline Média & 270,52 & 149,56 & 2,27 \\
Valor P & 0,3646 & 0,1578 & 0,2195 \\
CV $(\%)$ & 2,93 & 4,01 & 4,52 \\
\hline
\end{tabular}

$\mathrm{P}>0,05=$ não significativo; $0,05 \geq \mathrm{P} \geq 0,01=$ significativo ao nível de $5 \%$ de probabilidade; $\mathrm{P}<0,01=$ significativo ao nível de 5\% de probabilidade. Tratamento 1: aplicação de $1 / 2$ dose do bioestimulante em V4 + aplicação de 1/2 dose em V8 (T1); tratamento 2: aplicação de dose recomenda do bioestimulante em V4 (T2); tratamento 3: aplicação de dose recomenda do bioestimulante em V8 (T3); tratamento 4: nitrogênio (T4); tratamento 5: nitrogênio + aplicação de dose recomenda do bioestimulante em V8 (T5); tratamento 6: nitrogênio + aplicação de dose recomenda do bioestimulante em V4 (T6); tratamento 7: sem nitrogênio e sem bioestimulante (testemunha) (T7).

Quanto ao nitrogênio, os resultados corroboram com Dotto et al. (2010) os quais avaliaram dois híbridos de milho, cultivados com diferentes níveis de nitrogênio em milho e não observaram diferenças para as variáveis altura de inserção da espiga e diâmetro do colmo. Porém, para a utilização de ácidos húmicos/fúlvicos no cultivo de milho, tem-se observado modificação da arquitetura radicular, principalmente com surgimento de raízes laterais, após a aplicação de ácidos húmicos (ZANDONADI et., 2010), porém não são encontrados trabalhos que avaliam as características morfológicas da parte área das plantas, ao final do ciclo da cultura.

Quanto aos componentes de rendimento, a variável fileiras por espiga não apresentou diferença entre os tratamentos estudados, sendo observado média de 16,4 fileiras (Tabela 2). Corroborando com Mortate et al. (2018), em que testando diferentes fontes de nitrogênio, inclusive uréia $(45 \%)$ não observaram diferenças 
estatísticas sobre a variável número de fileiras por espiga.

Tabela 2. Ácidos húmicos/fúlvicos e nitrogênio sob os componentes de rendimento de milho, cultivado na safra 2017/2018. Dois Vizinhos - PR (2018).

\begin{tabular}{cccc}
\hline Tratamentos & Grãos por fileira & Fileiras por espigas & Grãos por espiga \\
\hline T1 & $29,25 \mathrm{~b}$ & 16,10 & $470,88 \mathrm{~b}$ \\
T2 & $29,75 \mathrm{~b}$ & 16,10 & $479,64 \mathrm{~b}$ \\
T3 & $31,10 \mathrm{~b}$ & 16,30 & $507,06 \mathrm{~b}$ \\
T4 & $35,25 \mathrm{a}$ & 16,50 & $581,44 \mathrm{a}$ \\
T5 & $34,85 \mathrm{a}$ & 16,60 & $578,26 \mathrm{a}$ \\
T6 & $33,70 \mathrm{a}$ & 17,00 & $572,94 \mathrm{a}$ \\
T7 & $27,75 \mathrm{~b}$ & 16,20 & $451,00 \mathrm{~b}$ \\
\hline Média & 31,66 & 16,40 & 520,17 \\
Valor P & 0,0001 & 0,4919 & 0,0000 \\
CV $(\%)$ & 5,10 & 4,12 & 7,08 \\
\hline
\end{tabular}

$\mathrm{P}>0,05=$ não significativo; $0,05 \geq \mathrm{P} \geq 0,01=$ significativo ao nível de $5 \%$ de probabilidade; $\mathrm{P}<0,01=$ significativo ao nível de 5\% de probabilidade. Letras diferentes na coluna, diferem estatisticamente pelo teste de Scott-Knott a 5\% de probabilidade. Tratamento 1: aplicação de 1/2 dose do bioestimulante em V4 + aplicação de 1/2 dose em V8 (T1); tratamento 2: aplicação de dose recomenda do bioestimulante em V4 (T2); tratamento 3: aplicação de dose recomenda do bioestimulante em V8 (T3); tratamento 4: nitrogênio (T4); tratamento 5: nitrogênio + aplicação de dose recomenda do bioestimulante em V8 (T5); tratamento 6: nitrogênio + aplicação de dose recomenda do bioestimulante em V4 (T6); tratamento 7: sem nitrogênio e sem bioestimulante (testemunha) (T7).

Segundo Magalhães et al. (2006), é no estádio V8 que o número de fileiras de grãos é definido. Sabendo que parte dos tratamentos foram implantados em estádio V4, esperava-se constatar efeito dos tratamentos nesta variável, fato não observado.

Já as variáveis: número de grãos por fileira e número de grãos por espiga apresentaram diferenças significativas entre os tratamentos analisados, sendo observado maiores médias naqueles que receberam nitrogênio em cobertura (T4, T5 e T6) (Tabela 2).

Este resultado demonstra a importância que o nitrogênio apresenta sobre os componentes de rendimento do milho. Portela et al. (2016) relatam a importância do nitrogênio para o metabolismo das plantas, uma vez que, está ligado a síntese dos fotoassimilados e de outras substâncias essenciais para a elaboração de moléculas de proteínas, aminoácidos e amido, contribuindo, no caso do milho, para a formação de espigas e logo, número de grãos por espigas.

A extração de nitrogênio, fósforo, potássio, cálcio e magnésio aumenta linearmente com o aumento na produção de grãos, sendo que a maior exigência da cultura do milho refere-se a nitrogênio e potássio, desta forma, quando ocorre deficiência de nitrogênio, se tem como resultado, uma redução expressiva na massa de grãos e espigas, gerando espigas com porte pequeno e não satisfatória comercialmente (Portela et al. 2016).

A menor quantidade de grãos por fileira, que influenciou a redução do número de grãos por espiga nos tratamentos sem a presença de nitrogênio, foi nitidamente observado no momento da colheita das PEs. Os tratamentos sem utilização de nitrogênio (T1, T2 e T3) apresentavam espigas de menor porte e grãos de tamanho reduzido na sua parte final (Figura 2 (A) (B) (C)). Por outro lado, observou-se que as espigas provenientes das PEs que haviam recebidos 
adubação nitrogenada em cobertura (T4, T5 e T6), apresentavam porte superior e com grãos até a parte final da espiga (Figura 2 (D) (E) (F)), colaborando assim, com o aumento do número de grãos por fileira e $o$ aumento da quantidade de grãos nestes tratamentos, fato este afirmado pelo teste estatístico (Tabela 2).

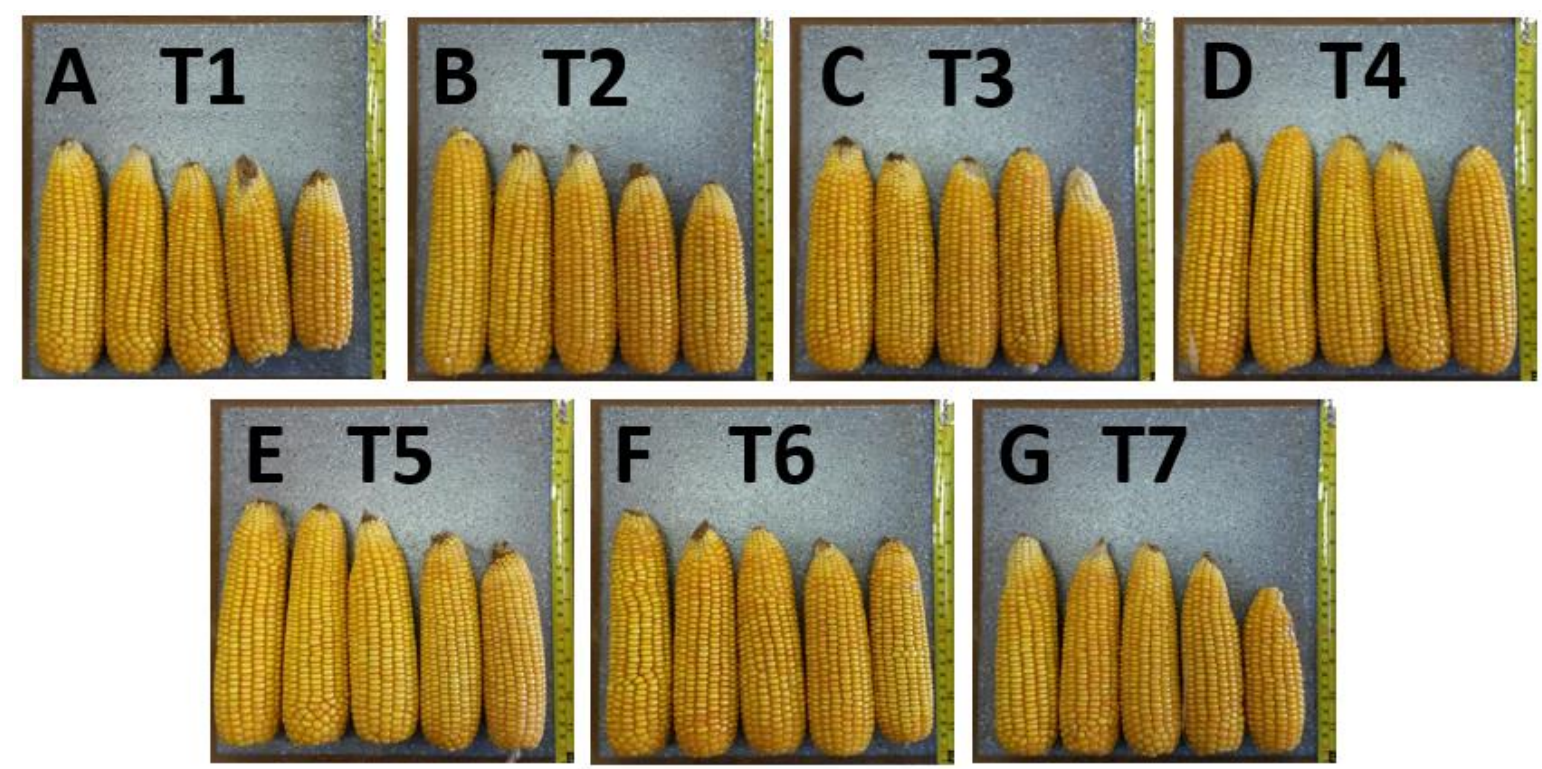

Figura 2. Espigas das parcelas experimentas dos tratamentos avaliados: Tratamento 1: aplicação de $1 / 2$ dose do bioestimulante em V4 + aplicação de 1/2 dose em V8 (T1 - A); tratamento 2: aplicação de dose recomenda do bioestimulante em V4 (T2 - B); tratamento 3: aplicação de dose recomenda do bioestimulante em V8 (T3 - C); tratamento 4: nitrogênio (T4 - D); tratamento 5: nitrogênio + aplicação de dose recomenda do bioestimulante em V8 (T5 - E); tratamento 6: nitrogênio + aplicação de dose recomenda do bioestimulante em V4 (T6 - F); tratamento 7: sem nitrogênio e sem bioestimulante (testemunha) (T7 - G). Fotos: Vanderson Vieira Batista.

Além do número de grãos por espiga, outros fatores importantes que devem ser considerados para que o produtor obtenha sucesso no rendimento produtivo das lavouras de milho, é o estande de plantas e a quantidade de espigas por área. Vian et al. (2016) relatam que a obtenção de alta produtividade de grãos na cultura do milho está diretamente condicionada a população final de plantas, com distribuição espacial de plantas uniforme e com o mínimo possível de plantas dominadas na área.

$\mathrm{O}$ estande de plantas não foi avaliado no presente estudo e observou-se que o número de espigas não foi influenciado estatisticamente pelos tratamentos avaliados, contatando valor médio de 74.683 espigas $\mathrm{ha}^{-1}$ (Tabela 3). Esta semelhança estatística para o número de espigas (Tabela 3), associada ao baixo coeficiente de variação (CV) observado para a variável $(3,48 \%)$, sugere que as UA apresentavam homogeneidade entre os tratamentos avaliados.

Sabe-se, que os híbridos modernos de milho, apresentam como características a formação de somente uma espiga por planta (SANGOI, 2000). Neste contexto, supõemse que a população de plantas, na lavoura experimental, era próxima à quantidade espigas da área. Sendo assim, é considerada baixa $(4,3 \%)$ a quantidade de sementes que não germinaram e/ou de plantas perdidas durante a condução do estudo, analisando que a densidade de semeadura foi de 80.000 sementes ha ${ }^{-1}$. Fato este, pode ser atribuído a boa distribuição das sementes na lavoura, realizada por uma semeadoura/adubadora de 
precisão, com sistema a vácuo, contribuindo para que não tenha sido observada a ocorrência de plantas dominadas e competição intraespecífica na lavoura, proporcionando homogeneidade entre os tratamentos e cooperando para que não observou-se diferenças estatísticas entre os tratamentos estudados.

Tabela 3. Ácidos húmicos/fúlvicos e nitrogênio sob os componentes de rendimento de milho, cultivado na safra 2017/2018. Dois Vizinhos - PR (2018).

\begin{tabular}{cccccc}
\hline Tratamentos & $\begin{array}{c}\text { Espigas } \\
\left(\text { espigas ha }^{-1}\right)\end{array}$ & $\begin{array}{c}\text { Umidade } \\
(\%)\end{array}$ & $\begin{array}{c}\text { Massa de mil } \\
\text { grãos }(\mathrm{g})\end{array}$ & $\begin{array}{c}\text { Produtividade } \\
\left(\mathrm{Kg} \mathrm{ha}^{-1}\right)\end{array}$ & $\begin{array}{c}\text { Produtividade } \\
\text { por espiga }(\mathrm{g})\end{array}$ \\
\hline T1 & $75.555,56$ & 28,90 & $353,03 \mathrm{~b}$ & $10.412,16 \mathrm{~b}$ & $137,80 \mathrm{~b}$ \\
T2 & $75.000,00$ & 29,45 & $344,61 \mathrm{~b}$ & $9.925,07 \mathrm{~b}$ & $132,57 \mathrm{~b}$ \\
T3 & $72.777,78$ & 29,30 & $347,56 \mathrm{~b}$ & $9.624,23 \mathrm{~b}$ & $132,24 \mathrm{~b}$ \\
T4 & $76.111,11$ & 29,13 & $359,54 \mathrm{a}$ & $12.132,43 \mathrm{a}$ & $159,49 \mathrm{a}$ \\
T5 & $74.444,44$ & 28,98 & $369,49 \mathrm{a}$ & $11.985,88 \mathrm{a}$ & $161,37 \mathrm{a}$ \\
T6 & $73.888,89$ & 28,35 & $364,47 \mathrm{a}$ & $12.198,20 \mathrm{a}$ & $164,92 \mathrm{a}$ \\
T7 & $75.000,00$ & 29,20 & $343,57 \mathrm{~b}$ & $9.593,45 \mathrm{~b}$ & $127,80 \mathrm{~b}$ \\
\hline Média & $74.682,54$ & 29,04 & 354,61 & 10838,77 & 145,17 \\
Valor P & 0,6368 & 0,9581 & 0,0459 & 0,0000 & 0,0000 \\
CV $(\%)$ & 3,48 & 5,03 & 3,52 & 7,26 & 7,17 \\
\hline
\end{tabular}

$\mathrm{P}>0,05=$ não significativo; $0,05 \geq \mathrm{P} \geq 0,01=$ significativo ao nível de $5 \%$ de probabilidade; $\mathrm{P}<0,01=$ significativo ao nível de $5 \%$ de probabilidade. Letras diferentes na coluna, diferem estatisticamente pelo teste de Scott-Knott a 5\% de probabilidade. Tratamento 1: aplicação de 1/2 dose do bioestimulante em V4 + aplicação de $1 / 2$ dose em V8 (T1); tratamento 2: aplicação de dose recomenda do bioestimulante em V4 (T2); tratamento 3: aplicação de dose recomenda do bioestimulante em V8 (T3); tratamento 4: nitrogênio (T4); tratamento 5: nitrogênio + aplicação de dose recomenda do bioestimulante em V8 (T5); tratamento 6: nitrogênio + aplicação de dose recomenda do bioestimulante em V4 (T6); tratamento 7: sem nitrogênio e sem bioestimulante (testemunha) (T7).

Assim como a quantidade de espigas por área, a variável umidade dos grãos, também não apresentou diferença estatística (Tabela 3). Este resultado evidencia que os tratamentos apresentaram comportamento semelhante para os fatores avaliados (ácidos húmicos/fúlvicos e nitrogênio), de tal forma que os fatores não interferiram no desenvolvimento/ciclo da cultura do milho, resultando em porcentagens de umidade nos grãos ao final do ciclo, semelhantes.

Porém, observa-se na Tabela 3, diferenças estatísticas entre os tratamentos estudados para as variáveis de massa de mil grãos, produtividade $\left(\begin{array}{lll}\mathrm{Kg} & \left.\mathrm{ha}^{-1}\right) & \mathrm{e}\end{array}\right.$ produtividade por espiga, sendo constado os maiores valores nos tratamentos que receberam adubação nitrogenada em cobertura para ambas as variáveis. Resultados semelhantes também foram encontrados por Mortate et al. (2018) onde avaliando diferentes fontes de nitrogênio sobre a cultura do milho, verificaram maior massa de mil grãos e maior produtividade no tratamento composto por $200 \mathrm{Kg} \mathrm{ha}^{-1}$ de ureia (45\% de N), dosagem esta, semelhante a empregada no presente estudo.

Dotto et al. (2010) observaram em seus estudos que a utilização de $80 \mathrm{Kg} \mathrm{ha}^{-1}$ de nitrogênio é o suficiente para diferir estatisticamente do tratamento sem nitrogênio. Argenta et al. (2002) destacam que a necessidade para produção de uma tonelada de grãos de milho varie de 20 a $28 \mathrm{Kg} \mathrm{ha}^{-1}$ de N, evidenciando ainda mais a importância que o nutriente representa para a cultura, principalmente sobre ao rendimento produtivo.

Porém, não são observadas diferenças entre os tratamentos que 
receberam somente ácidos húmicos/fúlvicos (T1, T2 e T3) (Figura 2 (A) (B) (C)) e o tratamento testemunha (T7) (Figura $2(\mathrm{G})$ ), para as variáveis de características agronômicas de plantas de milho (Tabela 1), tampouco para as variáveis de componentes de rendimento (Tabela 2, Tabela 3) da cultura do milho.

Estudos mostram que os ácidos húmicos e fúlvicos apresentam potencial de aumentar o desenvolvimento do sistema radicular de plantas, podendo incrementar também a biomassa da parte aérea (CARON et al., 2015), fatos estes, que acreditava-se, que poderiam contribuir com o rendimento produtivo da cultura do milho. Porém os pesquisadores destacam que a dose e a cultura, a ser aplicado os ácidos, ainda precisa ser determinadas com base em ensaios.

Também, segundo Caron et al. (2015), a escolha e a aplicação dos ácidos húmicos deve ser criteriosa, levando em consideração a cultura a ser manejada, o solo de cultivo, nutrientes e defensivos agrícolas a serem utilizados, pois estas substâncias auxiliam positivamente a estrutura física e química do solo, além de incrementarem a biomassa radicular e da parte aérea nas plantas.

No presente estudo, não foi realizada uma análise prévia dos componentes físicos e químicos do solo, porém, sabe-se que o solo da área experimental apresenta bons índices de fertilidade e que há anos é cultivado em sistema de plantio direto, com rotação de culturas e elevados índices de investimento em adubação químico. Sousa et al. (2003) constataram em seus estudos que o sistema em plantio direto de milho, tanto em monocultura como em sucessão com leguminosas, apresentam migração de ácido fúlvico para as camadas mais profundas, reduzindo os teores de matéria húmica na camada superficial do solo, e proporciona interconversão de ácido fúlvico e ácido húmicos mais rápida.

Neste contexto, percebe-se que diversos fatores podem estar interferindo na ação dos ácidos húmicos/fúlvicos no estudo. Acredita-se que o longo histórico de plantio direto empregado na área, associado ao elevado nível de investimento, com adição de $300 \mathrm{~kg} \mathrm{ha}^{-1}$ de adubo químico (13-34-00 $\mathrm{NP}_{2} \mathrm{O}_{5} \mathrm{~K}_{2} \mathrm{O}$ ), podem ter contribuindo para que não houvesse efeito dos ácidos húmicos/fúlvicos sob as características morfológicas de plantas e sob os componentes de rendimento da cultura do milho. Também, estudos que buscam identificar a época, forma e quantidade de substância a ser utilizada, devem ser realizados, a fim de identificar a melhor forma de utilização da substância.

Apesar de não haver diferença estatística entre o tratamento testemunha (T7) e os tratamentos que receberam somente o bioestimulante (T1, T2 e T3) (Tabela 3), constata-se que os tratamentos que receberam o produto, apresentaram produtividade numericamente superior. Observa-se na Tabela 3 , produtividade de $10.412 \mathrm{Kg} \mathrm{ha}^{-1}$, no tratamento constituído de aplicação de $1 / 2$ dose da recomendação técnica do produto em V4 + 1/2 dose em V8 (T1), ou seja, produtividade superior em 819 $\mathrm{Kg} \mathrm{ha}{ }^{-1}$, em relação ao tratamento testemunha (T7) (9.593 $\left.\mathrm{Kg} \mathrm{ha}^{-1}\right)$. Sabendo, que o custo do bioestimulante é de aproximadamente $\mathrm{R} \$ 28 \mathrm{ha}^{-1}$, e que se aplicado $312,5 \mathrm{~mL}$ em V4 ( $1 / 2$ dose) e mais $312,5 \mathrm{~mL}$ em V8 (1/2 dose) (T1), a cultura do milho respondera com aumento de $819 \mathrm{~kg}$ $\mathrm{ha}^{-1}$ na produtividade, estes valores devem ser levados em consideração pelo produtor rural, pois o produto apresenta potencial para elevar a produtividade da lavoura. 


\section{CONCLUSÕES}

Nas condições de realização do estudo, os ácidos húmicos/fúlvicos não interferiram nas características morfológicas de plantas, tampouco sobre os componentes de rendimento da cultura do milho, seja estes utilizados isoladamente ou em associação ao nitrogênio.

\section{REFERÊNCIAS}

ALVARES, C.A.; STAPE, J.L.; SENTELHAS, P.C.; MORAES, G.; LEONARDO, J.; SPAROVEK, G. Köppen's climate classification map for Brazil. Meteorologische Zeitschrift, v. 22, n. 6, p. 711-728, 2013.

ARGENTA, G.; SILVA, P.R.F.; MIELNICZUK, J., BORTOLINI, C.G. Parâmetros de planta como indicadores do nível de nitrogênio na cultura do milho. Pesquisa Agropecuária Brasileira, v. 37, n. 4, p. 519-527, abr. 2002.

BHERING, S. B.; Mapa de solos do Estado do Paraná, Rio de Janeiro - RJ, p. 73, 2007.

CARON, V.C.; GRAÇAS, J.P.; CASTRO, P.R.C. Condicionadores do solo: ácidos húmicos e fúlvicos. Piracicaba: ESALQ/USP, 2015.

COELHO, A.M; FRANÇA, G.E. Nutrição e adubação de milho. In: EMBRAPA. Centro de Nacional de Pesquisa de Milho e Sorgo. Relatório técnico anual do Centro Nacional de Pesquisa de Milho e Sorgo. 1988-1991. Sete Lagoas, 1992. p. 25.

CONAB. Companhia Nacional de Abastecimento. Safra Brasileira de Grãos 2017/18 - Levantamento da Conab. (Março 2018) Versão eletrônica. Disponível em: < http://www.conab.gov.br/conteudos.php?a=1 $253 \& \mathrm{t}=2 />$ Acesso em: 03/04/2018.
A utilização de nitrogênio em cobertura proporciona na cultura do milho aumento do número de grãos por fileira e grãos por espiga, massa de mil grãos e produtividade por espiga e por área.

DOTTO, A.P.; LANA, M.C.; STEINER, F.; FRANDOLOSO, J.F. Produtividade do milho em resposta à inoculação com Herbaspirillum seropedicae sob diferentes níveis de nitrogênio. Revista Brasileira de Ciências Agrárias. v.5, n.3, p.376-382, jul.set., 2010.

DUPONT PIONNER, (2018). Disponível em:

<http://www.pioneersementes.com.br/milho/ central-de-produtos/produtos/30f53vyhr >

Acesso em: 03/08/2018.

FERREIRA, D. F. Sisvar: um programa para análises e ensino de estatística. Revista Científica Symposium, 6:36-41, 2008.

IAPAR. Instituto Agronômico do Paraná. Zoneamento da cultura do milho $2^{\mathrm{a}}$ safra no Paraná: mapas. Versão eletrônica. Disponível em: < http://www.iapar.br/modules/conteudo/conte udo.php? conteudo=1089> . Acesso em: 24/03/2018.

LANGE, A.; CAIONE, G.; SCHONINGER, E.L.; SILVA, R.G. Produtividade de milho safrinha em consórcio com capim-marandu em função de fontes e doses de nitrogênio em cobertura. Revista Brasileira de Milho e Sorgo, v. 13, n. 1, p. 35-47, 2014. 
MAGALHÃES, P.C.; DURÃES, F.O.M. Fisiologia da produção de milho. Circular técnica 76. Sete Lagoas, MG. 2006.

MORTATE, R.K. NASCIMENTO, E.F., GONÇALVES, E.G.S, LIMA, M.W.P. Resposta do milho (Zea mays L.) à adubação foliar e via solo de nitrogênio. Revista de Agricultura Neotropical, v. 5, n. 1, p. 1-6, 2018.

NETO, A.P.; CAMARGOS, A.E.V.; VALERIANO, T.B.; SGOBI, M.A.; SANTANA, M.J. Doses de nitrogênio para cultivares de milho irrigado. Nucleus, v. 13, n. 1, p. 87-96, 2016.

OLIVEIRA, N.T.; SOUSA, S.M. Avaliação de plântulas de milho sob efeito de bioestimulantes em solução nutritiva. Embrapa Milho e Sorgo-Boletim de Pesquisa e Desenvolvimento (INFOTECAE). 2016.

PANDOLFO, C.M.; VOGT, G.A.; BALBINOT JÚNIOR, A.A.; GALLOTTI, G. J. M.; ZOLDAN, S.R. Desempenho de milho inoculado com Azospirillum brasiliense associado a doses de nitrogênio em cobertura. Revista Agropecuária Catarinense. v.27, n.3, p. 94-99, 2015.

PORTELA, M.G.T. ARAÚJO, R.L., BARBOSA, R.P., ROCHA, D.R. Características agronômicas do milho submetido a fontes e parcelamento de nitrogênio em cobertura. Revista Brasileira de Engenharia de Biossistemas, v. 10, n. 3, p. 248-258, 2016

SANGOI, L. A compreensão dos efeitos da densidade de plantas sobre o crescimento e desenvolvimento do milho é importante para maximizar o rendimento de grãos. Ciência
Rural, Santa Maria, v.31, n.1, p.159-168, 2000.

SOUSA, W.J.O.; MELO, W.J. matéria orgânica em um latossolo submetido a diferentes sistemas de produção de milho. Revista Brasileira de Ciência do Solo, 27:1113-1122, 2003.

USDA. United States Department of Agriculture, (Departamento de Agricultura dos Estados Unidos. Safra Mundial de Milho 2015/16 - $14^{\circ}$ Levantamento do USDA. Informativo DEAGRO (Departamento do Agronegócio da FIESP) Versão eletrônica, Abril, 2017. Disponível em: $<\mathrm{http}: / /$ www.fiesp.com.br/indices-pesquisase-publicacoes/safra-mundial-de-milho2/>Acesso em: 01/04/2018.

VIAN, A.L.; SANTI, A.L.; AMADO, T.J.C.; CHERUBIN, M.R.; SIMON, D.H.; DAMIAN, J.M.; BREDEMEIER, C. Variabilidade espacial da produtividade de milho irrigado e sua correlação com variáveis explicativas de planta. Ciência Rural, v. 46, n. 3, p. 464-471, 2016.

ZANDONADI，D.B.; CANELLAS， L.P.; FAÇANHA, A.R. Indolacetic and humic acids induce lateral root development through a concerted plasmalemma and tonoplast $\mathrm{H}+$ pumps activation. Planta, Berlin, v. 225, p. 1583-1595, 2007.

ZAMPONADI, D.B.; SANTOS, M.P.; DOBBSS, L.B.; OLIVARES, F.L.; CANELLAS, L.P.; BINZEL, M.L.; OKOROKOVA-FAÇANHA, A.L.; FAÇANHA, A.R. Nitric oxide mediates humic acidsinduced root development and plasma membrane H+ATPase activation. Planta, Heidelberg, v. 231, n. 5, p. 10251036, 2010. 